Monika Szturmowicz', Inga Barańska², Małgorzata Ewa Jędrych', Iwona Bartoszuk', Piotr Radwan-Roehrenschef', Adriana Roży ${ }^{3}$, Iwona Bestry ${ }^{2}$, Joanna Chorostowska-Wynimko', Renata Langfort ${ }^{4}$, Jan Kuś

${ }^{1} 1^{\text {st }}$ Department of Lung Diseases, National Tuberculosis and Lung Diseases Research Institute, Warsaw, Poland ${ }^{2}$ Department of Radiology and Diagnostic Imaging National Tuberbulosis and Lung Diseases Research Institute, Warsaw, Poland ${ }^{3}$ Department of Genetics and Clinical Immunology, National Tuberculosis and Lung Diseases Research Institute, Warsaw, Poland ${ }^{4}$ Department of Pathology, National Tuberculosis and Lung Diseases Research Institute, Warsaw, Poland

\title{
Hypersensitivity pneumonitis recognised in a single pulmonary unit, between 2005 and 2015: comparison with recently proposed diagnostic criteria
}

\begin{abstract}
Introduction: Hypersensitivity pneumonitis (HP) is the third most common interstitial lung disease after idiopathic pulmonary fibrosis and nonspecific interstitial pneumonia. Pathogenesis of HP is related to repeated exposure to inhaled environmental antigens that sensitise the susceptible, genetically predisposed persons.

The aim of the present retrospective study was to summarise the diagnostic methods used in consecutive patients with $\mathrm{HP}$, recognised in a single pulmonary unit, between 2005 and 2015, and to compare them with current diagnostic criteria.

Material and methods: 135 patients, 68 males, 67 females, median age 53 years (18-75 years), entered the study. Chest CT features characteristic of HP were defined as: mosaic attenuation of lung parenchyma, air trapping and/or ill-defined centrilobular nodules. Lymphocytosis in BAL was defined as $\geq 30 \%$.

Results: Median time from first symptoms to diagnosis was 12 months. The exposure to one or more allergens was found in $94 \%$ of patients, chest CT features characteristic of HP have been reported in $87 \%$, BAL lymphocytosis — in $86 \%$.

According to recent diagnostic criteria — in $54 \%$ of patients, clinical diagnosis of HP was confident, in $16 \%$ — probable, in $26 \%$ — possible and in $4 \%$ - unlikely. The confirmation of HP with lung biopsy has been obtained in $36 \%$ of non-confident cases (16\% of the study group). Conclusion: HP diagnosis was confirmed according to current diagnostic criteria in 70\% of patients diagnosed between 2005 and 2015. Contradictions to lung biopsy have been the main reason for inability to confirm HP in non-confident cases.
\end{abstract}

Key words: hypersensitivity pneumonitis, diagnostic criteria, high resolution chest computed tomography, bronchoalveolar lavage Adv Respir Med. 2019; 87: 83-89

\section{Introduction}

Hypersensitivity pneumonitis (HP) is the third most common interstitial lung disease after idiopathic pulmonary fibrosis (IPF) and nonspecific interstitial pneumonitis (NSIP) [1, 2]. The incidence rate of HP has been calculated as 0.9/100 000/ year in the United Kingdom [3], 1/100000/year in Denmark [1], and 1.28-1.94/100000/year in the US [4]. The data concerning HP epidemiology in Poland confirmed the incidence rate of 1.26/100 000 in 1990-1994 [5] and 1.7/100 000 in 2000-2009 [6].
Pathogenesis of HP is related to repeated exposure to inhaled environmental antigens that sensitise the susceptible, genetically predisposed persons. The causative agents are divided into 6 groups: bacteria, fungi, mycobacteria, animal and plant proteins, chemicals and metals [7, 8]. Most of inducing antigens are avian proteins (bird keepers' lung, feather duvet lung), nevertheless, the exposure to microorganisms/ mould containing aerosols (humidifier lung, air conditioner lung, hot tub lung, summer-type HP ) or to microorganisms/mould colonising hay and straw (farmer's lung) are also frequently described [9-12].

Address for correspondence: Monika Szturmowicz, $1^{\text {st }}$ Department of Lung Diseases, National Tuberculosis and Lung Diseases Research Institute, Plocka 26, 01-138 Warsaw, Poland, e-mail: monika.szturmowicz@gmail.com DOI: 10.5603/ARM.2019.0014

Received: 21.12.2018

Copyright (C) 2019 PTChP

ISSN 2451-4934 
Two clinical phases of HP are distinguished presently: acute phase $(<6$ months, with pulmonary pathology fully reversible) and chronic phase $(\geq 6$ months, with irreversible lung changes) [13]. The prolonged exposure to the antigens may result in chronic inflammatory lung disease with pro-fibrotic phenotype [14].

Systemic manifestations of HP consist of general malaise, increased body temperature, arthralgia or muscle pain, which develop usually few hours after the antigen exposure [15]. Pulmonary symptoms, such as productive or non-productive cough, chest tightness, decrease of exercise tolerance and/or exertional dyspnoea are most frequent manifestations of chronic HP. On auscultation, transient bibasilar crackles are noted in the acute phase of disease, whereas inspiratory rales, wheezing, or inspiratory squeaks are described in chronic phase $[13,16]$.

Most characteristic radiological features of HP described in chest computed tomography (chest CT) in the acute phase are the following: mosaic lung attenuation, with the areas of ground glass opacities and air trapping (so called "head cheese” appearance), and/or ill-defined centrilobular nodules $[10,16]$. Upper and middle parts of the lungs are mostly affected [16]. Chest CT changes described in chronic phase of HP consist mostly of foci of peribronchovascular fibrosis and honeycombing, which may occur in any zonal distribution, with relative sparing of the lung bases. Nevertheless, mosaic attenuation, air trapping and areas of ground glass attenuation often persist [17].

Many algorithms of HP recognition have been proposed recently, but none of them is recommended as the universal mode of HP diagnosing.

The general agreement is that the diagnostic path of HP has to be composed of several steps:

1. Identification of agent possibly responsible for the symptoms of the disease (via detailed anamnesis). Demonstration of specific IgG antibodies against various antigens in serum of exposed persons, which is helpful only in patients with symptomatic disease.

2. Identification of characteristic radiological pattern of changes on chest CT.

3. Increased cellularity and lymphocytosis in bronchoalveolar lavage (BAL).

4. Characteristic pattern of lung pathology in the specimen obtained on transbronchial lung biopsy (TBLB) or transbronchial cryobiopsy (TBCB): the presence of poorly formed granulomas and/or inflammatory infiltration composed of lymphocytes and plasmocytes, with bronchocentric distribution [13, 18].
5. Surgical lung biopsy (SLB) should be considered if the diagnosis of HP is uncertain, despite the implementation of the above mentioned procedures.

The aim of the present retrospective study was to summarise the diagnostic methods used in the patients with HP recognised in a single pulmonary unit between 2005 and 2015 and to compare them with current diagnostic criteria proposed recently [13].

\section{Material and methods}

All the consecutive patients discharged between 2005 and 2015 with the diagnosis of HP entered the study. The data concerning exposure to antigens as well as signs and symptoms of the disease have been obtained from medical records. Time from the first symptoms appearance to diagnosis has been calculated. The data concerning radiological pattern of chest CT changes as well as BAL results have been elicited from the hospital database. The description of pathological changes in the lung biopsy specimens have been obtained from the Department of Pathology.

The criteria of chest CT features characteristic of HP have been described as: mosaic attenuation of lung parenchyma with the presence of air trapping and/or ill-defined centrilobular nodules (Fig. 1A, B). In case of lung fibrosis, signs of air trapping and persisting features of mosaic attenuation have been regarded characteristic (Fig. 2A, B).

Lymphocytosis in BAL was defined as equal or higher than $30 \%$. This arbitrary cut-off has been chosen, as it exceeds twice the upper limit of reference value in our laboratory. It also corresponds to suggestions of other authors $[15,19,20]$.

The pathological reports have been considered characteristic of HP in case of chronic bronchiolitis with lymphoplasmacytic infiltrations and/or poorly formed non-necrotising granulomas or at least - with solitary giant cells (Fig. 3). The bronchiolocentric distribution of inflammatory or fibrotic lesions have been also classified as the pathological feature of HP. The infective cause of granulomas have been excluded by specific tissue staining for acid fast bacilli (Ziehl-Neelsen) or fungi (Grocott).

For analysis of HP probability, according to recently proposed algorithm, the authors applied diagnostic categories defined by Vasakova et al. [13] (Fig. 4). 

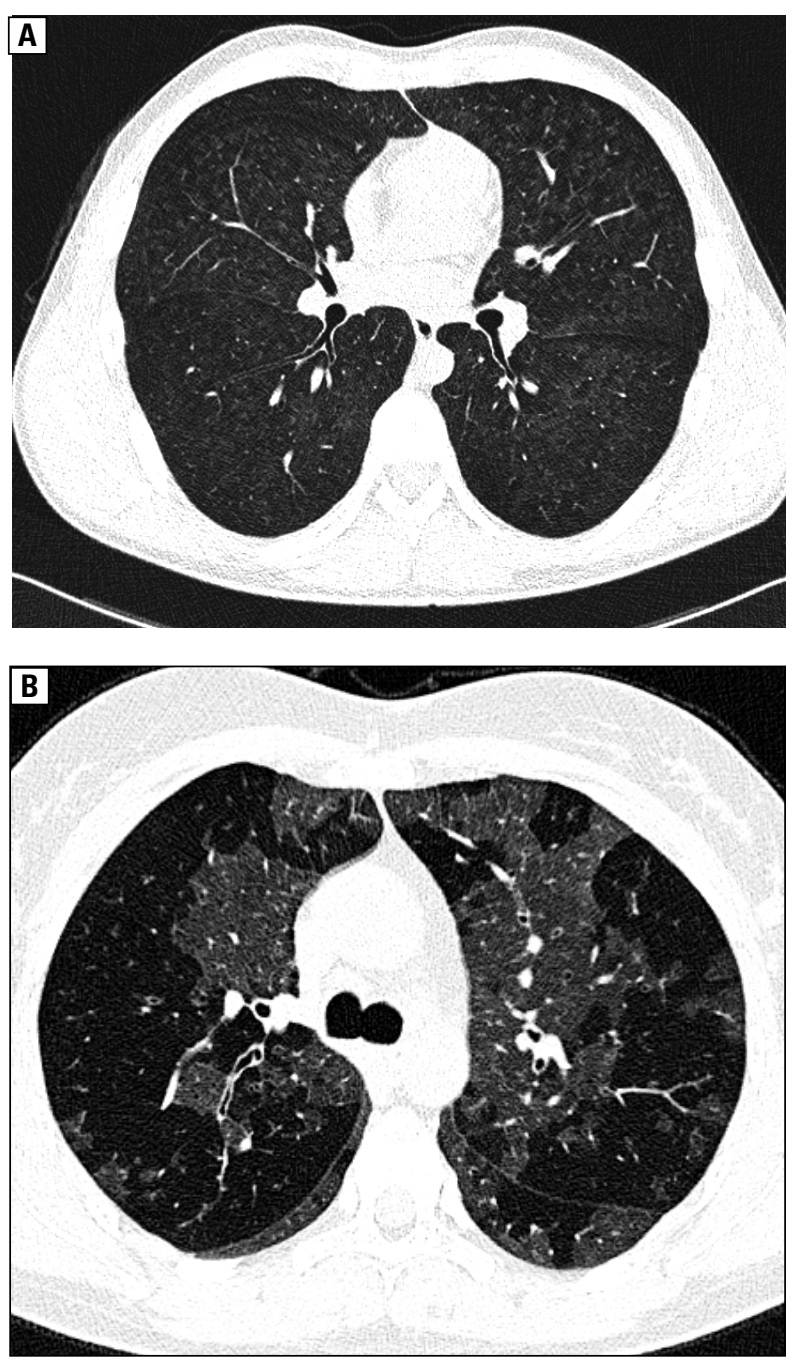

Figure 1. Acute HP, HRCT on inspiration, axial view; $\mathbf{A}$ - case 1. Poorly defined centrilobular nodules, some of them confluent; B - case 2 . Areas of ground glass opacities and of air trapping causing mosaic lung attenuation pattern

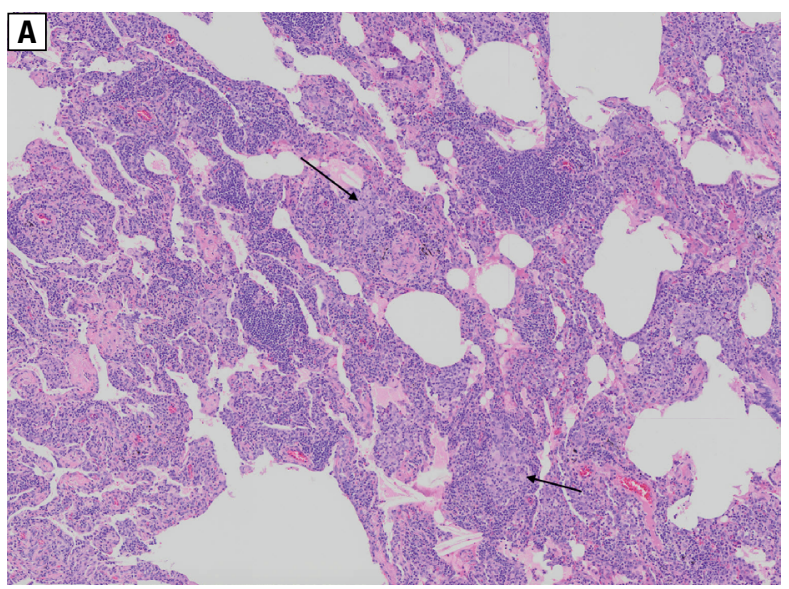

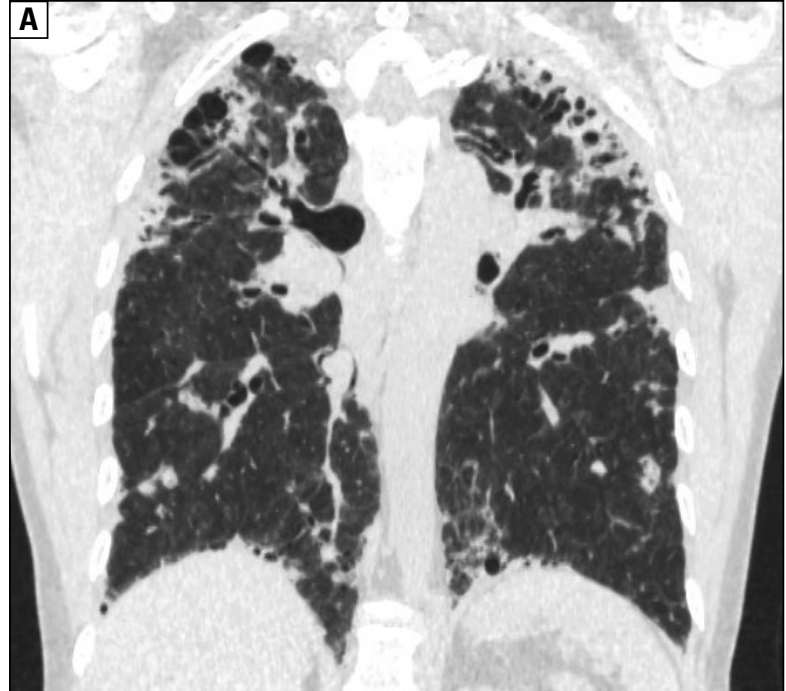

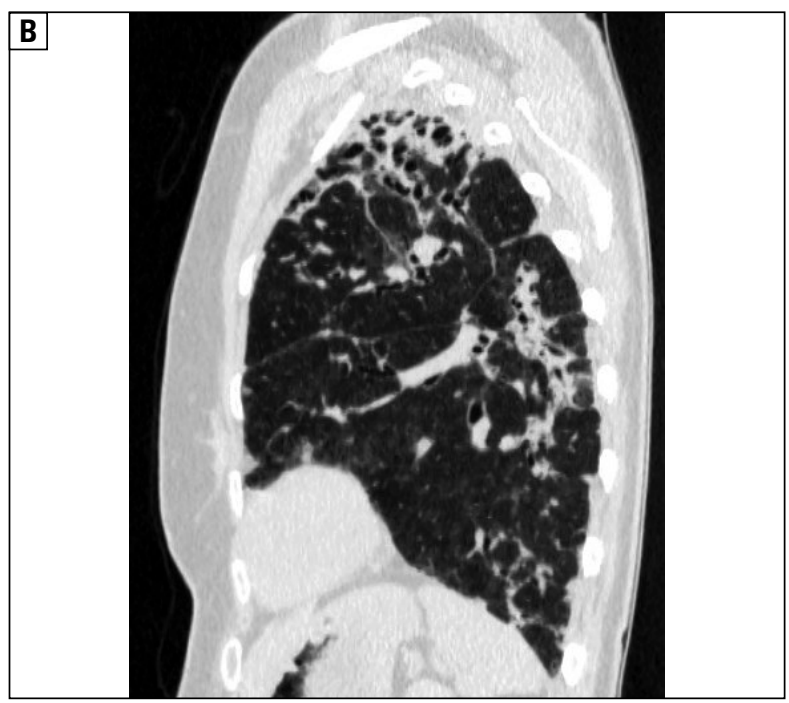

Figure 2. Case 3 - chronic HP, chest CT on inspiration; A - frontal view, B - coronal view. Patchy fibrosis with traction bronchiectasis and honeycombing with superimposed ground glass opacities and some centrilobular nodules, upper lung predominance

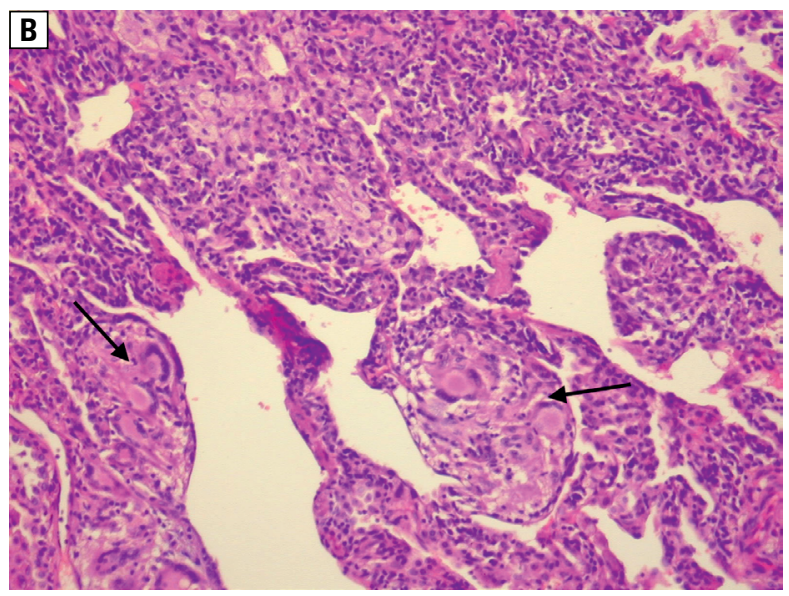

Figure 3. Hypersensitivity pneumonitis, microscopic image; A — lung parenchyma section with diffuse, uniform inflammatory infiltration of lymphocytes and plasmocytes, without destruction of parenchyma. Among the inflammatory infiltration there are poorly formed granulomas (arrows). Low magnification; B - lung parenchyma with two weakly formed granulomas composed mainly of giant cells (arrows). High magnification 


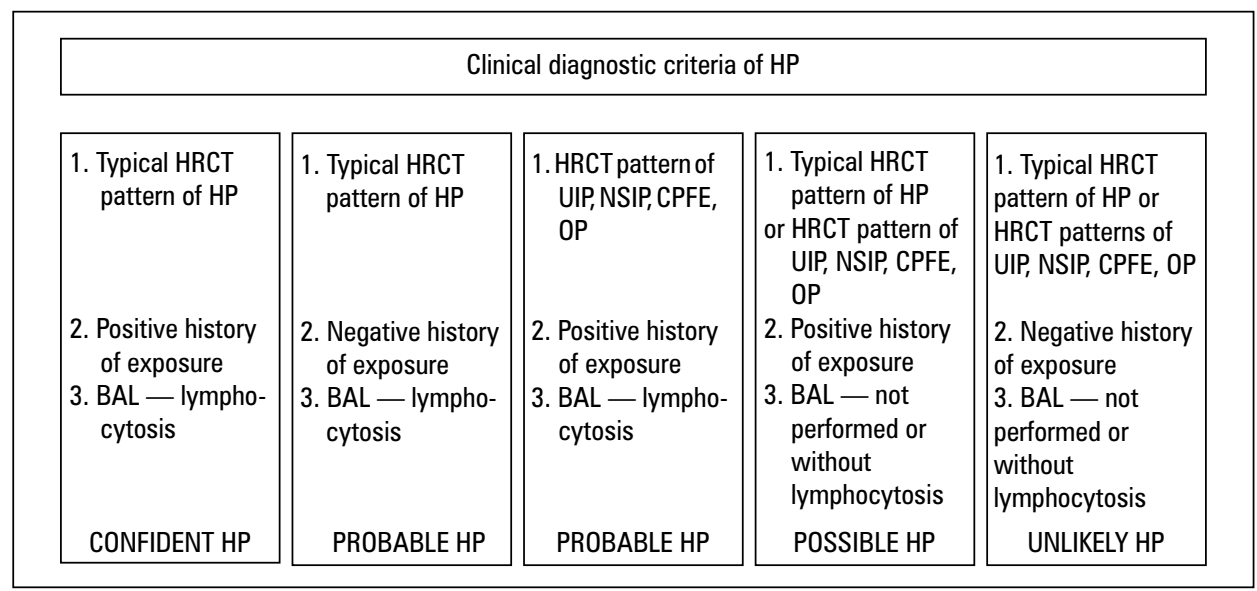

Figure 4. Clinical HP probability algorithm

The study has been approved by the Bioethical Committee of National Tuberculosis and Lung Diseases Research Institute No 14/2019

\section{Results}

Medical database contained 135 records of patients discharged with the diagnosis of HP ( ICD 10: J67.0-9) in between 2005 and 2015. There were 68 males, 67 females, median age 53 years (18-75 years).

The median time from first symptoms to diagnosis of HP was 12 months (range - 2 months to 30 years). In 15 patients the disease has been symptomatic for the period shorter than 6 months, in 56 - between 6 and 12 months, in 25 - between 12 and 24 months, in 32 - for over 24 months. Four patients have been diagnosed in childhood due to interstitial lung disease.

Data obtained from anamnesis revealed the exposure to one or more allergens in 127 of HP patients (94\%): poultry — in 40 patients, pigeons — in 29 patients, parrots - in 10 pts, microorganisms present in hay and hay products - in 51 patients, other exposures - in 28 cases. In 18 subjects - the contact with allergens was not confirmed. Precipitins to birds' proteins have been found in 68 patients, the precipitins to thermophilic bacteria present in hay products - in 26 patients.

Chest CT results have been available in all of the patients. The features characteristic of HP have been reported in 117 subjects (87\%). In the remaining ones - lung fibrosis without characteristic pattern of HP has been described.

BAL has been performed in 109 patients. Lymphocytosis exceeding $30 \%$ was found in 94 out of 109 patients (86\%). In 6 patients BAL lym- phocyte count was between $20 \%$ and $30 \%$, in the remaining 9 - it was lower than $20 \%$.

Transbronchial lung biopsy (TBLB) was performed in 37 patients, HP diagnosis has been confirmed - in 18 (49\%). Surgical lung biopsy (SLB) was carried out in 40 subjects (in 5 - after negative result of transbronchial lung biopsy). The diagnosis of HP has been confirmed in 35 cases (88\%).

Basing on the obtained data, the patients have been classified according to the categories described by Vasakova et al. [13]. In 73 patients (54\%), the diagnosis of HP has been confident, in $21(16 \%)$ - probable, in $35(26 \%)$ - possible and in $6(4 \%)$ - unlikely. Among 21 patients with probable diagnosis of HP - the reason for such classification has been the lack of confirmation of exposure - in 12 patients, or lack of characteristic chest CT features of HP - in 9. Among the patients with possible diagnosis of HP, the lack of BAL was the reason for such classification in 22 , and lymphocytosis lower than $30 \%$ - in 13 patients.

Data concerning the results of lung biopsy in different diagnostic categories have been presented in Table 1.

Lung biopsy has been performed in 41 out of 73 patients with confident diagnosis. All 19 SLBs (100\%) and 11 out of 24 TBLBs (46\%) have been positive. Among 13 biopsies conducted in 21 patients with probable diagnosis, 9 have been positive: 6 out of 7 SLBs (86\%) and 3 out of 6 TBLBs (50\%). Among 17 biopsies performed in 35 patients with possible diagnosis, 10 have been positive: 7 out of 10 SLBs (70\%) and 3 out of 7 TBLBs (43\%). Among 4 surgical biopsies carried out in 6 patients with unlikely diagnosis, 3 have been positive $(75 \%)$. 
Table 1. Lung biopsy results, according to different diagnostic clinical categories in 77 hypersensitivity pneumonitis (HP) patients

\begin{tabular}{|c|c|c|c|c|c|}
\hline \multirow[t]{2}{*}{ Type of biopsy } & \multicolumn{5}{|c|}{ Clinical diagnostic category of HP } \\
\hline & $\begin{array}{c}\text { Confident } \\
\text { no }(\%)\end{array}$ & $\begin{array}{c}\text { Probable } \\
\text { no (\%) }\end{array}$ & $\begin{array}{c}\text { Possible } \\
\text { no (\%) }\end{array}$ & $\begin{array}{l}\text { Unlikely } \\
\text { no (\%) }\end{array}$ & $\begin{array}{c}\text { Total } \\
\text { no (\%) }\end{array}$ \\
\hline \multicolumn{6}{|l|}{ TBLB } \\
\hline Positive & $11(46 \%)$ & $3(50 \%)$ & $3(43 \%)$ & 0 & $17(46 \%)$ \\
\hline Negative & 13 & 3 & 4 & 0 & 20 \\
\hline Total & 24 & 6 & 7 & 0 & 37 \\
\hline \multicolumn{6}{|l|}{ SLB } \\
\hline Positive & $19(100 \%)$ & $6(86 \%)$ & $7(70 \%)$ & $3(75 \%)$ & $35(88 \%)$ \\
\hline Negative & 0 & 1 & 3 & 1 & 5 \\
\hline Total & 19 & 7 & 10 & 4 & 40 \\
\hline
\end{tabular}

TBLB: transbronchial lung biopsy; SLB: surgical lung biopsy

Overall, the confirmation of HP with lung biopsy results have been obtained in 9 out of 21 probable cases of HP (43\%), 10 out of 35 possible cases of HP (29\%), and in 3 out of 6 unlikely cases (50\%).

Thus, in 95 out of 135 patients (70\%) with HP recognised in the period of 2005-2015, the diagnosis could be confirmed according to recently proposed diagnostic criteria: in $54 \%$ due to confident clinical diagnosis, in $16 \%$ with nonconfident diagnosis - after confirmation with lung biopsy. The reason for the lack of proof of HP in $30 \%$ of the subjects was as follows: negative SLB - in 4\%, and contraindications to invasive diagnostic procedures - in $26 \%$.

\section{Discussion}

HP, recognised in our centre in 135 patients, fulfilled the current diagnostic criteria in 95 cases (70\%), in 73 - due to confident clinical diagnosis, and in 22 with non-confident clinical diagnosis - due to positive result of lung biopsy.

First step of HP recognition, the identification of causative antigen, has been shown in $94 \%$ of patients. These data indicate the high rate of antigen confirmation in the presented material, other authors documented positive history of exposures in $70-89 \%$ of patients $[12,21]$. Most frequent exposures in the present study concerned contacts with dump hay or hay products, poultry and pigeons. In $6 \%$ of patients, the causative agent has not been identified. As the list of described allergens is enlarging, medical anamnesis has to be composed of many questions, to confirm the occupational, or environmental exposure [13].

Precipitins to birds' antigens have been discovered in 68 patients (in 48 of them, the exposure to birds proteins have been confirmed). The presence of precipitins to birds' antigens in the patients without confirmed exposure, but otherwise fulfilling the criteria of HP, may be of clinical value in HP diagnosing.

The median time to diagnosis was 12 months, in 120 subjects (88\%) it was longer than 6 months. Thus, according to current classification, the majority of patients presented with chronic HP.

Radiological pattern of HP, which is very characteristic in the acute phase of the illness, may be more difficult to recognise in the chronic phase, especially when the distribution of fibrotic areas mimic nonspecific interstitial pneumonia (NSIP) or usual interstitial pneumonia (UIP). Nevertheless, in our material, in 117 out of 135 patients (87\%), features characteristic of HP have been present in chest CT. Most of the patients presented with mosaic lung attenuations and occasionally - with air trapping. Upper and middle parts of the lungs have been most extensively affected. The recent publication of Salisbury et al. [17] has indicated that predominance of mosaic attenuation and air trapping over reticulation are most predictive of HP in chronic phase of disease.

Comparing to other interstitial lung diseases, HP is presenting with highest number of lymphocytes in BAL. There is no consensus in the literature concerning the measures that would be useful in HP diagnosing, the proposed cut-off values range from $20 \%$ to $50 \%$ [15, 22]. Higher cut-offs have to be probably used in case of differential diagnosis between HP and such interstitial lung diseases as: sarcoidosis, organising pneumonia or NSIP $[8,15]$. In chronic phase of HP, lymphocyte counts may be lower, especially in smokers [8, $12,13,23]$. In our material, BAL lymphocytosis exceeding 30\% was found in 94 out of 109 pa- 
tients (86\%), despite the fact that the majority of them presented with chronic disease. On grounds of this finding, we suggest BAL performance in every patient with HP suspicion, even in those with fibrotic lung disease. It may be especially important in case of fibrotic HP mimicking UIP, as in UIP patients, the percentage of lymphocytes in BAL is usually below $20 \%$ [21].

Transbronchial lung biopsy has been diagnostic of HP in $46 \%$ of patients. The percentage of positive TBLB results have been comparable in all diagnostic categories of HP, indicating that the results are mostly influenced by lower sensitivity of this method comparing to SLB, and not by clinical HP probability. Surgical lung biopsy produced much higher diagnostic yield in our material, confirming the HP diagnosis in $88 \%$ of patients (in $100 \%$ of confident cases, but also in $70-86 \%$ of the remaining categories).

According to current recommendations, patients with confident clinical diagnosis of HP wouldn't be referred to surgical lung biopsy. Nevertheless, in our study group, the qualification for SLB has been performed between 2005 and 2015, and many patients were referred to our Surgical Department from other centres.

Despite lower sensitivity of TBLB comparing to SLB, in our opinion, the patients with non-confident clinical diagnosis of HP should be first referred to TBLB, because it is less invasive and combined with fewer complications [24]. In the period of 2005-2015, we had no experience with transbronchial cryobiopsy. The results obtained recently by other authors are encouraging [13, 15].

On the basis of the obtained data, we conclude that every effort should be made to enlarge the number of patients diagnosed as confident HP. Most important steps include the following:

1. Identification of responsible antigen via detailed anamnesis.

2. Clinical and radiological consulting in case of less typical radiological disease appearance.

3. Performing BAL (in search of increased lymphocytosis) in all suitable patients with HP suspicion.

\section{Conflict of interest}

The authors declare no conflict of interest.

\section{Acknowledgements}

The authors would like to thank Mrs. Karolina Noskowska for her perfect technical assistance.

\section{References:}

1. Hyldgaard C, Hilberg O, Muller A, et al. A cohort study of interstitial lung diseases in central Denmark. Respir Med. 2014; 108(5): 793-799, doi: 10.1016/j.rmed.2013.09.002, indexed in Pubmed: 24636811.

2. Rowińska-Zakrzewska E, Bestry I, Szturmowicz M. Alergiczne zapalenie pęcherzyków płucnych. In: Śródmiąższowe choroby płuc: Interna Szczeklika 2018. Medycyna Praktyczna, Kraków 2018: 768-771.

3. Solaymani-Dodaran M, West J, Smith C, et al. Extrinsic allergic alveolitis: incidence and mortality in the general population. QJM. 2007; 100(4): 233-237, doi: 10.1093/qjmed/hcm008, indexed in Pubmed: 17307752.

4. Fernández Pérez ER, Kong AM, Raimundo K, et al. Epidemiology of hypersensitivity pneumonitis among an insured population in the United States: a claims-based cohort analysis. Ann Am Thorac Soc. 2018; 15(4): 460-469, doi: 10.1513/ AnnalsATS.201704-288OC, indexed in Pubmed: 29236517.

5. Meleniewska-Maciszewska A, Kuś J, Wesołowski S, et al. Częstość rozpoznawania alergicznego zapalenia pęcherzyków płucnych w Polsce w latach 1990-1994. Pneumonol Alergol Pol. 1997; 65(3-4): 205-210.

6. Szafrański W. Analiza grupy chorych na śródmiąższowe choroby płuc hospitalizowanych w latach 2000-2009 na oddziale płucnym wojewódzkiego szpitala w Radomiu. Pneumonol Alergol Pol. 2012; 80(6): 523-532.

7. Nogueira R, Melo N, Novais E Bastos H, et al. Hypersensitivity pneumonitis: Antigen diversity and disease implications. Pulmonology. 2018 [Epub ahead of print], doi: 10.1016/j.pulmoe.2018.07.003, indexed in Pubmed: 30126802.

8. Morell F, Villar A, Ojanguren I, et al. Hypersensitivity pneumonitis: challenges in diagnosis and management, avoiding surgical lung biopsy. Semin Respir Crit Care Med. 2016; 37(3): 395-405, doi: 10.1055/s-0036-1580692, indexed in Pubmed: 27231863.

9. Sema M, Miyazaki Y, Tsutsui T, et al. Environmental levels of avian antigen are relevant to the progression of chronic hypersensitivity pneumonitis during antigen avoidance. Immun Inflamm Dis. 2018; 6(1): 154-162, doi: 10.1002/iid3.202, indexed in Pubmed: 29168324.

10. Jędrych ME, Szturmowicz M, Bestry I, et al. Hypersensitivity pneumonitis: Diagnostic criteria, treatment, prognosis and prevention. Med Pr. 2016; 67(4): 517-527, doi: 10.13075/ mp.5893.00406, indexed in Pubmed: 27623832.

11. Jędrych ME, Kuś J. Alergiczne zapalenie pęcherzyków płucnych - epidemiologia, etiologia, immunopatogeneza, obraz kliniczny. Post Nauk Med. 2016; XXIX(1): 44-48.

12. Adams TN, Newton CA, Batra K, et al. Utility of bronchoalveolar lavage and transbronchial biopsy in patients with hypersensitivity pneumonitis. Lung. 2018; 196(5): 617-622, doi: 10.1007/s00408-018-0139-1, indexed in Pubmed: 29959521.

13. Vasakova M, Morell F, Walsh S, et al. Hypersensitivity pneumonitis: perspectives in diagnosis and management. Am J Respir Crit Care Med. 2017; 196(6): 680-689, doi: 10.1164/rccm. 201611-2201PP, indexed in Pubmed: 28598197.

14. Morell F, Villar A, Montero MÁ, et al. Chronic hypersensitivity pneumonitis in patients diagnosed with idiopathic pulmonary fibrosis: a prospective case-cohort study. Lancet Respir Med. 2013; 1(9): 685-694, doi: 10.1016/S2213-2600(13)70191-7, indexed in Pubmed: 24429272.

15. Salisbury ML, Myers JL, Belloli EA, et al. Diagnosis and treatment of fibrotic hypersensitivity pneumonia. Where we stand and where we need to go. Am J Respir Crit Care Med. 2017; 196(6): 690-699, doi: 10.1164/rccm.201608-1675PP, indexed in Pubmed: 28002680.

16. Pereira CAc, Gimenez A, Kuranishi L, et al. Chronic hypersensitivity pneumonitis. J Asthma Allergy. 2016; 9: 171-181, doi: 10.2147/JAA.S81540, indexed in Pubmed: 27703382.

17. Salisbury ML, Gross BH, Chughtai A, et al. Development and validation of a radiological diagnosis model for hypersensitivity pneumonitis. Eur Respir J. 2018; 52(2), doi: 10.1183/13993003.00443-2018, indexed in Pubmed: 29946001.

18. Churg A, Bilawich A, Wright JL. Pathology of chronic hypersensitivity pneumonitis what is it? What are the diagnostic 
criteria? Why do we care? Arch Pathol Lab Med. 2018; 142(1): 109-119, doi: 10.5858/arpa.2017-0173-RA, indexed in Pubmed: 28537805.

19. Wuyts W, Sterclova M, Vasakova M. Pitfalls in diagnosis and management of hypersensitivity pneumonitis. Curr Opin Pulm Med. 2015; 21(5): 490-498, doi: 10.1097/MCP.0000000000000199, indexed in Pubmed: 26176964.

20. Lacasse Y, Selman M, Costabel U, et al. HP Study Group. Clinical diagnosis of hypersensitivity pneumonitis. Am J Respir Crit Care Med. 2003; 168(8): 952-958, doi: 10.1164/rccm. 200301-137OC, indexed in Pubmed: 12842854.

21. Salisbury ML, Gu T, Murray S, et al. Hypersensitivity pneumonitis: radiologic phenotypes are associated with distinct survival time and pulmonary function trajectory. Chest. 2018 [Epub ahead of print], doi: 10.1016/j.chest.2018.08.1076, indexed in Pubmed: 30243979.

22. Morisset J, Johannson KA, Jones KD, et al. HP Delphi Collaborators. Identification of Diagnostic criteria for chronic hypersensitivity pneumonitis: an international modified delphi survey. Am J Respir Crit Care Med. 2018; 197(8): 1036-1044, doi: 10.1164/rccm.201710-1986OC, indexed in Pubmed: 29172641.

23. Woge MJ, Ryu JH, Moua T. Diagnostic implications of positive avian serology in suspected hypersensitivity pneumonitis. Respir Med. 2017; 129: 173-178, doi: 10.1016/j. rmed.2017.06.019, indexed in Pubmed: 28732828.

24. Raj R, Raparia K, Lynch DA, et al. Surgical lung biopsy for interstitial lung diseases. Chest. 2017; 151(5): 1131-1140, doi: 10.1016/j.chest.2016.06.019, indexed in Pubmed: 27471113. 